\title{
Evaluating the Impact of Health Insurance Industry Consolidation: Learning from Experience
}

The mission of The Commonwealth Fund is to promote a high performance health care system. The Fund carries out this mandate by supporting independent research on health care issues and making grants to improve health care practice and policy. Support for this research was provided by The Commonwealth Fund. The views presented here are those of the author and not necessarily those of The Commonwealth Fund or its directors, officers, or staff.

For more information about this brief, please contact:

Leemore S. Dafny

Professor of Strategy, Herman Smith Research Professor in Hospital and Health Services, and Director of Health Enterprise Management

Northwestern University Kellogg School of Management

l-dafnyakellogg.northwestern.edu
To learn more about new publications when they become available, visit the Fund's website and register to receive email alerts.

\section{Leemore S. Dafny}

\begin{abstract}
Research shows consolidation in the private health insurance industry leads to premium increases, even though insurers with larger local market shares generally obtain lower prices from health care providers. Additional research is needed to understand how to protect against harms and unlock benefits from scale. Data on enrollment, premiums, and costs of commercial health insurance-by insurer, plan, customer segment, and local market—would help us understand whether, when, and for whom consolidation is harmful or beneficial. Such transparency is common where there is a strong public interest and substantial public regulation, both of which characterize this vital sector.
\end{abstract}

\section{INTRODUCTION}

The public interest in ensuring competitive, robust private health insurance markets has never been greater. Today, nearly two-thirds of the U.S. population under age 65 is enrolled in a private comprehensive health plan. ${ }^{1}$ Private insurance is also playing an increasingly important role in supplying coverage to Americans in public programs, including Medicaid, which has experienced a rapid increase in enrollment as a result of the Affordable Care Act (ACA). Those who lack coverage and are ineligible for public coverage must purchase private policies to comply with the ACA's individual mandate.

At the same time, private insurance premiums $(\$ 16,834$ for the average family) and out-of-pocket spending ( $\$ 800$ per person) are high and projected to grow. Federal subsidies for individuals purchasing plans in the ACA's insurance marketplaces, meanwhile, are projected to total $\$ 37$ billion in 2015 and reach $\$ 87$ billion by $20200^{2,3}$

Given these stakes, there is a substantial public benefit to critically evaluating any significant changes in markets for private health insurance. This issue brief, based on my extensive review of public data and the economics research literature, examines consolidation in the health insurance industry and its impact on premiums and other outcomes of interest to consumers. I also consider how to assess the potential effects of future merger proposals. ${ }^{\dagger}$

$\dagger$ This issue brief was adapted from: L. S. Dafny, Testimony Before the Senate Committee on the Judiciary, Subcommittee on Antitrust, Competition Policy, and Consumer Rights, on "Health Insurance Industry Consolidation: What Do We Know from the Past, Is It Relevant in Light of the ACA, and What Should We Ask?” September 22, 2015. 


\section{MARKET CONCENTRATION IS HIGH AND INCREASING}

\section{Commercial Insurance}

Roughly 175 million Americans under age 65 purchased private insurance through their employers or the individual insurance market in 2013, the most recent year for which data are available. ${ }^{4}$ The industry has expanded since the ACA's marketplaces went online in 2014.

Exhibit 1 contains approximate estimates of the national market share of the four largest insurers over the period 2006-2014. With a few exceptions, Blue Cross Blue Shield (BCBS) affiliates have exclusive, nonoverlapping market territories and hence do not compete with one another. All 36 BCBS affiliates are therefore treated as a single firm for purposes of constructing the national fourfirm concentration ratio (the sum of market shares for the leading four firms), although market shares for the for-profit Blue plans (all operated by Anthem, Inc., and spanning 14 states today) are denoted separately in the exhibit.

Between 2006 and 2014, the four-firm concentration ratio for the sale of private insurance increased significantly, from 74 percent to 83 percent. By comparison, the four-firm concentration ratio for the airline industry is 62 percent. $^{5}$

\section{Exhibit 1. Estimated National Market Shares of the \\ Four Largest Insurers, 2006-2014}

100

$\begin{array}{lll} & & \text { Total } \\ \text { Total } & \text { Total } & 83 \% \\ 74 \% & 79 \% & \end{array}$

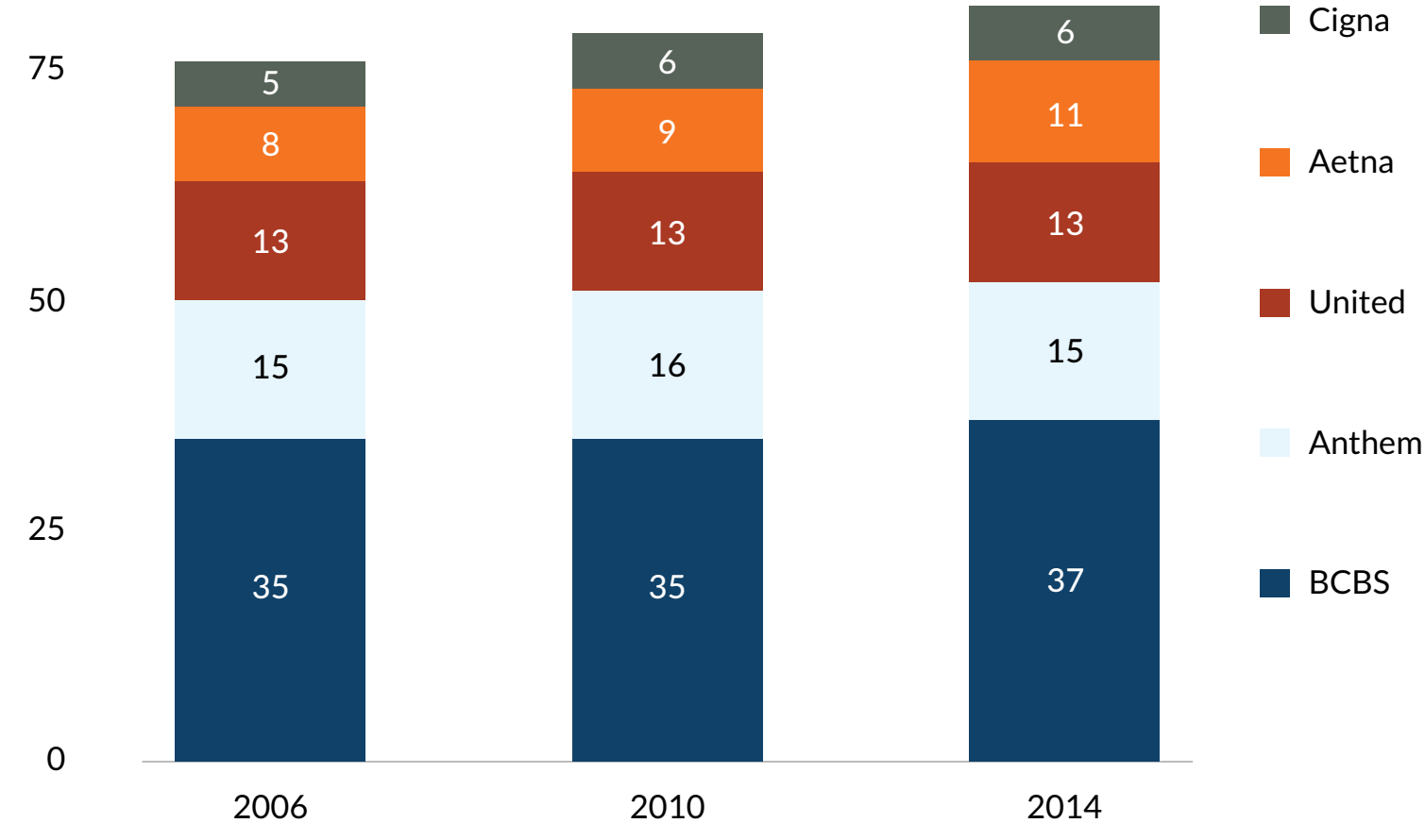


Exhibit 1 does not necessarily reflect the degree of concentration in insurance markets that are relevant to most consumers, however. Many health plans have a significant local, but not national, presence-Kaiser Permanente, Intermountain, and Geisinger among them. The degree of competition in any product and geographic market depends on the market participants and the characteristics of the products they offer. The American Medical Association's annual reports containing detailed market share information for the top two insurers show that concentration is higher within metropolitan statistical areas (MSAs), on average, than in the nation as a whole. Moreover, this concentration appears to be increasing over time. ${ }^{6}$

\section{Medicare Advantage}

Nearly 22 million Medicare beneficiaries are enrolled in government-financed private plans, collectively known as Medicare Advantage. Exhibit 2 shows a 13-percentage-point growth between 2011 and 2015 in the combined market shares of the four leading Medicare Advantage insurers. This market has experienced significantly more turbulence than the private insurance sector, owing to myriad changes in regulations and reimbursement rules. ${ }^{7}$ The national market leaders for Medicare Advantage differ somewhat from those in the private insurance market (which pools together fully and self-insured plans) but are the same for fully insured employer-sponsored plans. I estimate that 37 percent of Medicare beneficiaries live in counties where the Medicare Advantage market would be deemed "highly concentrated," per the Department of Justice and the Federal Trade Commission. ${ }^{8}$

\section{Exhibit 2. Medicare Advantage Four-Firm Concentration Ratio, 2007-2015}

75

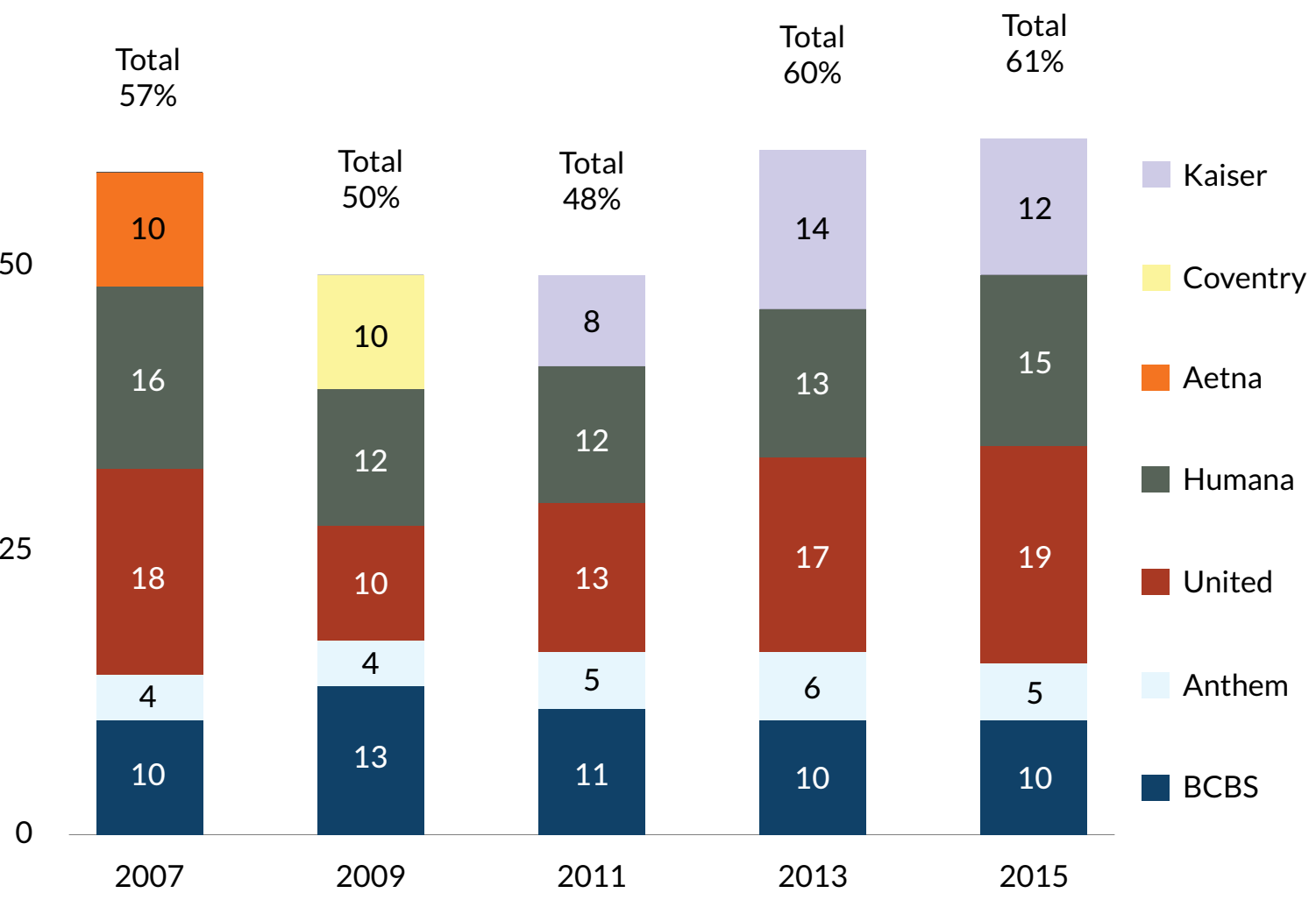




\section{Drivers of Industry Consolidation}

Most insurance industry consolidation in the past 20 years has been driven by mergers and by growth in the BCBS affiliates' market shares. ${ }^{9}$ These mergers can be categorized as:

- attempts by regional insurers to gain broader service areas;

- attempts by national insurers to obtain a presence in virtually all geographic areas;

- acquisitions of local HMOs and provider-sponsored plans by incumbents; or

- the consolidation of for-profit BCBS affiliates (into Anthem).

Some contend that recent or proposed insurance mergers are the result of the Affordable Care Act, but consolidation was already well under way before the law's passage. To the extent such consolidation is anticompetitive, it is at cross-purposes with the ACA. As Thomas Greaney, an expert on health care and antitrust law, recently observed, the ACA "does not regulate prices.... Instead the law relies on (1) competitive bargaining between payers and providers and (2) rivalry within each sector to drive price and quality to levels that best serve the public." 10

In fact, the ACA promotes competition in the insurance industry. For example, through regulatory reforms, the law fosters standardization of products and certifies plans, which reduce the hurdle to entry posed by the need to establish a credible reputation. The health insurance marketplaces, meanwhile, reduce marketing and sales costs, thereby raising the likelihood of entry. In fact, the marketplaces were explicitly designed to facilitate competition among insurers.

\section{WHAT HAVE WE LEARNED FROM CONSOLIDATION IN THE PAST?}

\section{Mergers lead to reduced payments to providers, but the cost savings are not passed through on average. There is limited evidence regarding the impact of consolidation on health plan quality.}

\section{Health care provider prices}

Several health economists have studied the correlation between hospital prices and market competitiveness, typically measured by the Herfindahl-Hirschman index, or HHI (see box). ${ }^{11}$ Although the $\mathrm{HHI}$ is an imperfect proxy for true competitiveness (the degree to which firms vie to serve consumers through product design, price, service, etc.), there are no alternative straightforward measures. Studies of hospital price and insurance HHI, which use different data sources and look at different time periods, generally find hospital prices are lower in geographic areas with higher levels of HHI-that is, where there is higher insurance market concentration. This relationship also holds when researchers study changes over time: in markets that are becoming more concentrated, there is slower growth in hospital prices.

But lower prices for health care services will benefit consumers only if they are ultimately passed through to consumers, in the form of lower insurance premiums or out-of-pocket charges. Even if price reductions are realized and passed through, if they are achieved as a result of monopsonization of health care markets, consumers may experience an offsetting harm. Monopsony-in which a large buyer, rather than seller, drives prices down-is the mirror image of monopoly; lower input prices are achieved by reducing the quantity or quality of services below the level that is socially optimal. $^{12}$ 


\section{HHI: A STANDARD MEASURE OF MARKET CONCENTRATION}

The Herfindahl-Hirschman Index $(\mathrm{HHI})$ is used by the Antitrust Division of the U.S. Department of Justice and the Federal Trade Commission to evaluate the potential antitrust implications of acquisitions and mergers across many industries, including health care. It is calculated by summing the squares of the market shares of individual firms.

Markets are classified as one of three categories: 1) nonconcentrated-HHI below 1,500;2) moderately concentrated-HHI between 1,500 and 2,500; and 3) highly concentrated-HHI above 2,500 .

Sources: U.S. Department of Justice and Federal Trade Commission, “Horizontal Merger Guidelines,” Aug. 2012.

A study of the 1999 Aetna-Prudential merger found a relative reduction in health care employment and wages in those geographic areas where there was more substantial market overlap between the two insurers. ${ }^{13}$ The implication is that the exercise of market power over health care providers reduced prices and output - the hallmark of monopsony.

However, in settings where both sides possess market power and bargain over prices, an increase in buyer power can reduce price without reducing output (or, equivalently, without leading to a deterioration in quality). Indeed, two other studies of monopsony focusing on hospitals - an industry that is concentrated in many areas-find areas with higher insurer HHIs (higher concentration) have higher, not lower, hospital utilization. ${ }^{14,15}$

\section{Health care quality}

Little published research exists on the link between consolidation and plan quality. The most relevant study to date, which pertains to the Medicare Advantage market, found that the availability of prescription drug benefits (before the enactment of Part D) was higher in areas with more rivals, all else equal. ${ }^{16}$ There is a vast literature concerning other health care settings that shows quality does not improve when markets become more consolidated. ${ }^{17}$ Although quality is more difficult to evaluate than price, the competitive mechanisms linking diminished competition to higher prices operate similarly with respect to lower quality.

\section{Insurance premiums}

Several studies document lower insurance premiums in areas with more insurers. These studies span a variety of segments, including the public health insurance marketplaces, the large-group market (selfinsured and fully insured plans combined), and Medicare Advantage. ${ }^{18,19,20}$ One recent study suggests premiums for self-insured employers are lower where insurer concentration is higher, but premiums for fully insured employers are higher. ${ }^{21}$

The best available evidence on the impact of consolidation comes from what are known as "event studies" or "merger retrospectives," such as the aforementioned Aetna-Prudential merger study. The researchers on that study found that premiums (for a pooled sample of self-insured and fully insured large-group plans) increased significantly more in areas with greater pre-merger market overlap. Moreover, the premium increase was not limited to the merging insurers; rival insurers raised premiums as well (in areas where the merging firms had substantial overlap). This is particularly notable in light of the fact that following the Aetna-Prudential merger, health care employment and wages were reduced. The cost savings were not passed on to consumers. 
A second study examined the impact of the 2008 merger of Sierra Health and UnitedHealth on small-group premiums in two Nevada markets. As compared with control cities in the South and West, small-group premiums in these markets increased by 13.7 percent the year following the merger. $^{22}$

Consolidation-induced premium increases generally have not been offset by competition from new entrants to private health insurance markets. Instead, entry into a given market has tended to occur through acquisition. New firms seeking to enter a market face a number of substantial challenges, including those related to:

- building networks of local providers and negotiating competitive reimbursement rates; ${ }^{23}$

- establishing a credible reputation with area employers and consumers;

- developing relationships with brokers, who serve as intermediaries for most purchasers; and

- achieving economies of scale in information technology, disease management, utilization review, and customer-service related functions.

In light of these and other impediments, consolidation even in nonoverlapping markets reduces the number of potential entrants that might attempt to overcome price-increasing (or qualityreducing) consolidation in markets where they do not currently operate.

\section{THE ACA DOES NOT DIMINISH THE NEED FOR INSURANCE MARKET COMPETITION}

\section{Effects of competition}

A reasonable question to ask is whether the experience of the Aetna-Prudential and UnitedHealthSierra Health mergers is informative in light of the significant recent changes brought about by the ACA. Early evidence suggests that competition continues to have salutary effects on health insurance markets, even in the post-ACA world. One study found that premiums on the individual exchanges in 2014 were more than 5 percent higher following the decision by a large national insurer not to participate in federally facilitated exchanges that year. ${ }^{24}$ In another study, researchers estimated that having an additional insurer in a given ratings area results in premium savings of nearly $\$ 500$ per individual. ${ }^{25}$

\section{Medical loss ratio regulations}

The ACA provision most relevant to the subject of insurer consolidation and its consequences concerns medical loss ratios (MLRs). As of 2011, insurers must devote at least 85 percent or 80 percent of premium revenues, net of taxes and licensing fees, to medical claims and quality improvement for their fully insured lives; the higher floor pertains to large-group customers while the lower floor applies to small groups and individuals. Insurers failing to satisfy these requirements must refund the shortfall to enrollees. Some have argued that these regulations mitigate concerns over potential anticompetitive consequences of consolidation in this sector. ${ }^{26}$ This argument is not convincing, however, for at least five reasons:

1. More than half of privately insured enrollees are in self-insured plans, and the minimum MLR regulations do not pertain to these plans. 
2. The MLR regulations attempt to cap industry profits but do not protect consumers from postmerger harm resulting from loss of competition on dimensions other than the share of spending devoted to medical claims and quality improvement activities. Such dimensions include innovative benefit designs, breadth and quality of provider networks, responsiveness of customer service, and quality of chronic disease management programs. Reducing the competition (or potential competition) via a merger may relax or eliminate competition on these dimensions.

3. For the MLR regulations to mitigate the adverse effects of consolidation, statutory floors must exceed the MLRs that would otherwise prevail. However, a recent study reports national MLRs for 2013 were 86 percent, 84 percent, and 89 percent for the individual, smallgroup, and large-group markets, respectively. ${ }^{27}$ These findings suggest there may be substantial room for profitable merger-related price increases in the individual market in particular, notwithstanding the minimum MLR requirement.

4. The MLR regulation could be gamed in a variety of ways by relabeling profits as costs. For example, insurers with ownership stakes in health care facilities and provider organizations could adjust internal transfer payments to these groups to ensure MLR minima are satisfied. Similarly, many insurers engaging in quality improvement efforts could create a separate quality improvement arm and charge the insurance arm fees that offset profits in excess of the MLR minima.

5. The minimum MLR regulation could be repealed. If transactions that would otherwise be deemed anticompetitive are not challenged under the belief that the regulation acts as a check on postmerger margin increases, what happens if a more consolidated insurance industry successfully argues for its repeal?

\section{Consolidation may enable insurers to implement or expedite productivity- enhancing changes to the health care delivery system, but this potential benefit remains speculative.}

The recent shift toward paying for value, rather than volume, of health care services will require significant changes in how insurers pay providers and how providers deliver and organize care. Some insurers have suggested that mergers will enhance their ability to develop and implement new valuebased payment agreements. ${ }^{28}$ But as yet there is no evidence that larger insurers are more likely to implement innovative payment and care management programs. Moreover, a countervailing force offsets the incentive to invest in such changes, even if scale reduces the costs of doing so: dominant insurers in a given insurance market are less concerned with the possibility of ceding market share.

Another open question is whether the benefits of scale in this regard pertain not only to combinations in the same relevant market but also to combinations across different insurance markets, that is, across different segments in the same geographic area or across different geographic areas in the same segment. For example, some have suggested that insurers with a broader geographic footprint will face lower per-enrollee costs for implementing value-based agreements. However, in actuality, national insurers may face greater difficulty in implementing new payment or care management models across disparate markets than local payers would face implementing such programs in a single area. This reality may explain why concerted delivery system reform efforts have tended to emerge 
from other sources, such as provider systems and state- or locally based payers like Massachusetts Blue Cross and Blue Shield.

Finally, the oft-repeated claim that some insurers will not be able to replicate or access valuebased payment without a merger should be treated with skepticism. Efficiencies must be mergerspecific and verifiable if they are to be credited against potential harm arising from diminished competition, and the question remains whether benefits will be passed through to consumers. Moreover, any short-term gain from avoiding development costs for value-based programs may be offset by a reduction in long-term benefits arising from competition among insurers to develop better versions of these programs.

\section{ROLES OF ENFORCERS, POLICYMAKERS, AND RESEARCHERS GOING FORWARD}

Some observers assume that federal and state antitrust enforcers will challenge transactions that are not likely to be beneficial to consumers. However, these agencies file suit if their investigations suggest that the transaction will "lessen competition" or "tend to produce a monopoly," per Section 7 of the Clayton Act. Ascertaining whether a transaction violates this central competition statute is a different matter from ascertaining whether it is in the public interest. For example, a merger that is likely to lead to price increases without offsetting benefits to consumers may not violate Section 7 if it cannot be shown that the merger lessens competition in a relevant antitrust market. Different stakeholders might also place different weights on the potential losses and gains for various affected parties.

Given the significance of the insurance sector to our wallets and to the functioning of our health care system, the public deserves better data with which to evaluate these transactions and the industry more generally. As a start, avenues must be found for requiring detailed reporting, at a local level (such as by zip code), on insurance enrollment, plan design, premiums, and medical loss ratios for every commercial health plan on offer. This reporting would ideally include self-insured plans, as more than half of the privately insured are enrolled in these types of plans. With these data, policymakers, researchers, and regulators would be able to monitor market developments and to intervene, if necessary, based on better and timelier information. 


\section{NOTES}

1 National Center for Health Statistics, "Early Release of Selected Estimates Based on Data From the National Health Interview Survey, 2014,” Table 1.2b (Hyattsville, Md.: NCHS, June 2015), http://www.cdc.gov/ nchs/data/nhis/earlyrelease/earlyrelease201506.pdf.

2 Kaiser Family Foundation and Health Research and Educational Trust, 2014 Survey of Employer Health Benefits (Menlo Park, Calif., and Chicago: Henry J. Kaiser Family Foundation and HRET, Sept. 2015), http://kff.org/health-costs/report/2014-employer-health-benefits-survey; Health Care Cost Institute, 2013 Health Care Cost and Utilization Report (Washington, D.C.: HCCI, Oct. 2014), http://www.healthcostinstitute.org/2013-health-care-cost-and-utilization-report.

3 Congressional Budget Office, Insurance Coverage Provisions of the Affordable Care Act—CBO's August 2015 Baseline (Washington, D.C.: CBO, Aug. 25, 2015), https://www.cbo.gov/publication/45069.

4 Per the U.S. Census Bureau's 2013 Current Population Survey (CPS) Annual Social and Economic (ASEC) Supplement, Table HI01, https://www.census.gov/hhes/www/cpstables/032014/health/h01R_000.htm.

5 U.S. Department of Transportation, Bureau of Transportation Statistics, "Airline Domestic Market Share July 2014-June 2015,” (Washington, D.C.: DOT), http://www.transtats.bts.gov/.

6 The American Medical Association reports are not strictly comparable over time because of changes in the number of MSAs included, and the inclusion of self-insured lives. The figures for 2012 include self-insured lives.

7 Total enrollment in Medicare Advantage has increased significantly over this period, from 9.3 million in 2007 to 22 million in 2015. Duggan, Starc, and Vabson show that reimbursement is strongly linked to entry. They estimate that for every dollar of additional reimbursement from the Medicare program, 20 cents is passed through to enrollees in the form of better coverage. M. Duggan, A. Starc, and B. Vabson, "Who Benefits When the Government Pays More? Pass-Through in the Medicare Advantage Program," No. w19989 (Washington, D.C.: National Bureau of Economic Research, March 2014), http://www.nber.org/ papers/w19989.

8 U.S. Department of Justice and Federal Trade Commission, Horizontal Merger Guidelines (Washington, D.C.: DOJ and FTC, 2010), http://www.ftc.gov/os/2010/08/100819hmg.pdf.

9 This growth precedes the period depicted in Exhibit 1. Per Ginsburg, "the relative position of the Blues strengthened with the loosening of managed care because of the diminishing importance of HMOs, which were generally a weak point for the Blues. Blue plans' ability to negotiate lower rates with providers on the basis of their large market share became more important." P. Ginsburg, "Competition in Health Care: Its Evolution Over the Past Decade," Health Affairs, Nov.-Dec. 2005 24(6):1512-22.

10 T. L. Greaney, "The State of Competition in the Health Care Marketplace: The Patient Protection and Affordable Care Act's Impact on Competition," United States House of Representatives Committee on the Judiciary, Subcommittee on Regulatory Reform, Commercial and Antitrust Law, Sept. 10, 2015, http:// judiciary.house.gov/_cache/files/0a0e88c8-0519-4a47-8fa8-4c2233c760c3/greaney-testimony.pdf.

11 G. A. Melnick, Y. C. Shen, and V. Y Yu, "The Increased Concentration of Health Plan Markets Can Benefit Consumers Through Lower Hospital Prices," Health Affairs, Sept. 2011 30(9):1728-33; A. S. Moriya, W. B. Vogt, and M. Gaynor, "Hospital Prices and Market Structure in the Hospital and Insurance Industries," Health Economics, Policy and Law, Oct. 2010 5(4):459-79; and E. E. Trish and B. J. Herring, "How Do Health Insurer Market Concentration and Bargaining Power with Hospitals Affect Health Insurance Premiums?" Journal of Health Economics, July 2015 42:104-14. All three rely on estimates of insurer HHI calculated from InterStudy data. Melnick et al. find that hospital prices in 2001-2004 are lower in MSAs with higher insurer HHI, provided the insurer HHI exceeds 3,200. Moriya et al. find that increases in MSAlevel insurer HHI between 2001 and 2003 are associated with decreases in hospital prices. Trish and Herring 
use more recent data (from 2006 to 2011) and find that hospital prices are lower among more concentrated insurance markets. United States House of Representatives, Committee on the Judiciary, Subcommittee on Regulatory Reform, Commercial and Antitrust Law, Sept. 10, 2015, http://judiciary.house.gov/_cache/ files/0a0e88c8-0519-4a47-8fa8-4c2233c760c3/greaney-testimony.pdf.

12 The way in which a monopsonistic insurance sector would achieve lower reimbursement rates is by setting a low market reimbursement rate, one which is beneath the value that some consumers place on those services. That is, there will be excess demand by consumers for services at this rate, and the monopsonist does not allow price to rise to expand output and equilibrate demand and supply.

13 L. Dafny, M. Duggan, and S. Ramanarayanan, "Paying a Premium on Your Premium? Consolidation in the U.S. Health Insurance Industry," American Economic Review, April 2012 102(2):1161-85.

14 Feldman and Wholey present evidence that prices are lower, but hospital utilization (a measure of quantity) is higher in markets with less competitive insurance markets. Similarly, McKellar et al. find in more concentrated insurer markets, health care prices are lower, utilization is higher, but overall spending is lower. R. Feldman and D. Wholey, "Do HMOs Have Monopsony Power?" International Journal of Health Care Finance and Economics, March 2001 1(1):7-22; and M. R. McKellar, S. Naimer, M. B. Landrum et al., "Insurer Market Structure and Variation in Commercial Health Care Spending," Health Services Research, June 2014 49(3):878-92.

15 Many health policy experts believe some types of health care services are overutilized. Where true, a quantity reduction arising from the exercise of monopsony power might be viewed as beneficial. However, this paternalistic approach to consumption is not ordinarily adopted by antitrust enforcers.

16 R. Town and S. Liu, "The Welfare Impact of Medicare HMOs," RAND Journal of Economics, Winter 2003 34(4):719-36.

17 See, for example, M. Gaynor and R. Town, The Impact of Hospital Consolidation (Princeton, N.J.: Robert Wood Johnson Foundation, June 2012), http:/www.rwjf.org/en/library/research/2012/06/the-impact-ofhospital-consolidation.html.

18 S. Sheingold, N. Nguyen, and A. Chappel, "Competition and Choice in the Health Insurance Marketplaces, 2014-2015: Impact on Premiums,” ASPE Issue Brief (Washington, D.C.: U.S. Department of Health and Human Services, July 30, 2015), http://aspe.hhs.gov/basic-report/ competition-and-choice-health-insurance-marketplaces-2014-2015-impact-premiums.

19 L. Dafny, M. Duggan, and S. Ramanarayanan, "Paying a Premium on Your Premium? Consolidation in the U.S. Health Insurance Industry," American Economic Review, April 2012 102(2):1161-85.

20 Z. Song, M. B. Landrum, and M. E. Chernew, "Competitive Bidding in Medicare: Who Benefits from Competition?” American Journal of Managed Care, Sept. 2012 18(9):546-52.

21 E. E. Trish and B. J. Herring, "How Do Health Insurer Market Concentration and Bargaining Power with Hospitals Affect Health Insurance Premiums?” Journal of Health Economics, July 2015 42:104-14.

22 J. R. Guardado, D. W. Emmons, and C. K. Kane, "The Price Effects of a Large Merger of Health Insurers: A Case Study of UnitedHealth-Sierra," Health Management, Policy and Innovation, June 2013 1(3):16-35.

23 This is a particularly salient barrier because of the chicken-and-egg problem of insurer-provider negotiations. Providers are generally willing to offer the most competitive rates to insurers with a large market share; however, to gain market share an insurer needs to offer low premiums (and to do so sustainably, must have competitive provider rates).

24 L. Dafny, J. Gruber, and C. Ody, "More Insurers, Lower Premiums: Evidence from Initial Pricing in the Health Insurance Marketplaces," American Journal of Health Economics, Winter 2015 1(1):53-81. 
25 M. J. Dickstein, M. Duggan, J. Orsini et al., “The Impact of Market Size and Composition on Health Insurance Premiums: Evidence from the First Year of the Affordable Care Act," American Economic Review, May 2015 105(5):120-25.

26 See, for example, CNBC, “Aetna, Humana CEOs Talk Antitrust Concerns,” July 6, 2015, http://video.cnbc. com/gallery/?video=3000394309.

27 M. J. McCue and M. A. Hall, The Federal Medical Loss Ratio Rule: Implications for Consumers in Year 3 (New York: The Commonwealth Fund, March 2015), p. 9.

28 For example, see Aetna's press release announcing the acquisition of Humana: "The combination will provide Aetna with an enhanced ability to work with providers and create value-based payment agreements that result in better care to consumers, and spread cutting-edge clinical practices and quality care." Aetna, "Aetna to Acquire Humana for $\$ 37$ Billion, Combined Entity to Drive Consumer-Focused, High-Value Health Care," July 3, 2015, https://news.aetna.com//news-releases/aetna-to-acquire-humana-for-37-billioncombined-entity-to-drive-consumer-focused-high-value-health-care/.

\section{ABOUT THE AUTHOR}

Leemore S. Dafny, Ph.D., is Professor of Strategy, the Herman Smith Research Professor in Hospital and Health Services, and Director of Health Enterprise Management at Northwestern University’s Kellogg School of Management. Her research examines competitive interactions among payers and providers of health care services, as well as the intersection of industry and public policy. Dafny's work has been published in journals such as the American Economic Review and the New England Journal of Medicine and featured in the New York Times, Business Week, Bloomberg, and the Washington Post. She currently serves on the Panel of Health Advisers for the Congressional Budget Office and previously was Deputy Director for Healthcare and Antitrust in the Bureau of Economics at the Federal Trade Commission.

\section{ACKNOWLEDGMENTS}

The author thanks Chris Ody and Victoria Marone, both of Northwestern University, for their assistance in preparing this brief and Zack Cooper, David Cutler, Mark Duggan, Pinar KaracaMandic, and Mark Shephard for their helpful comments.

Editorial support was provided by Hannah Fein and Chris Hollander. 
www.commonwealthfund.org 